\title{
Experimental studies of the various soils bedding influence on the stress-strain state of a layered subsoil base of the slab foundation
}

\author{
Lenar Siraziev ${ }^{1 *}[0000-0003-0379-0207]$, and Danil Sergeev ${ }^{1}$ \\ ${ }^{1}$ Kazan State University of Architecture and Engineering, 420043, Zelenaya st., Kazan, Russia
}

\begin{abstract}
The purpose of the study is to reveal the effect of the stressstrain state of the three-layer soil base of the slab foundation with a rigid underlying layer, which is heterogeneous along the depth of the ground. The main results of the study are obtaining relative deformations in the soil massif and the settlement of ground values of each layer. The results of experimental studies are obtained in the form of a deformation pattern of a layered base, distribution graphs of compressive stresses in the soil in depth and in a horizontal plane. The significance of the results achieved for the construction area is to establish the mutual influence of various soils on the stress-strain state of the laminate basement of the slab foundation. The presence of a dense top layer in a laminate base significantly increases its distribution ability. The stress distribution is proportional to the loadcarrying capacity of the individual base layers. On the boundary between the layers, a jump in the compressive stresses may occur, which indicates the presence of shear deformations in the contact layer.
\end{abstract}

Keywords: slab foundation, layered soil base, rigid underlay.

\section{Introduction}

Qualitative and dependable forecasting of stress-strain state of ground bases is urgent problem of modern urban construction. Real soil properties, layered foundation irregularities in depth which influence on the processes in ground bases that occur under external loads, should be best reflected in the used analytical models [1-5]. The development of reliable computational theory of layered ground bases becomes a hot topic at the present time when necessity of the high-rise buildings construction with slab foundations [6-10] under adverse engineering-geological conditions in modern large cities can be observed.

As a result it becomes necessary to receive experimental data about stress-strain state of layered foundations that will become the blueprint for development of actual models of ground bases with different strength and strain characteristics [11-15]. In order to obtain data on stress-strain state, it is necessary to conduct experimental study of the models of slab foundations on layered heterogeneous foundations are required [16-21].

\footnotetext{
*Corresponding author: siraziev100@mail.ru
} 


\section{Materials and methods}

The tests were carried out on volumetric laboratory metal flumes with dimensions of $100 \times 100 \mathrm{~cm}$ at the department of Foundations and basements, dynamics of structures and engineering geology of Kazan State University of Architecture and Engineering (KSUAE), general view of which is shown in Figs. 1, 2.

The model of layered foundation was formed by 3 layers of soil with different physical and mechanical characteristics, under which there was low-compressible layer. The height of three-layer foundation is $60 \mathrm{~cm}$; the height of lower underlayer is $40 \mathrm{~cm}$.

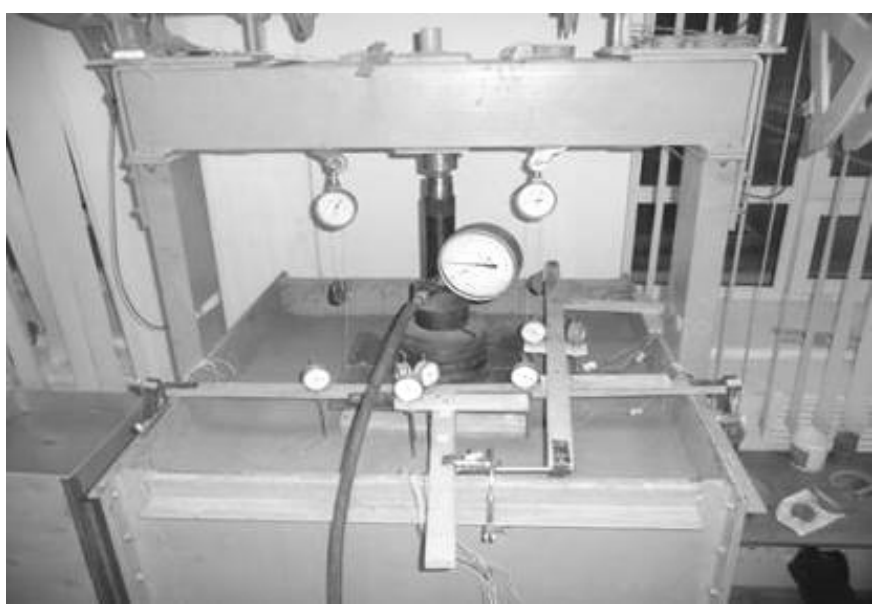

Fig. 1. General view of the laboratory flume under investigation.

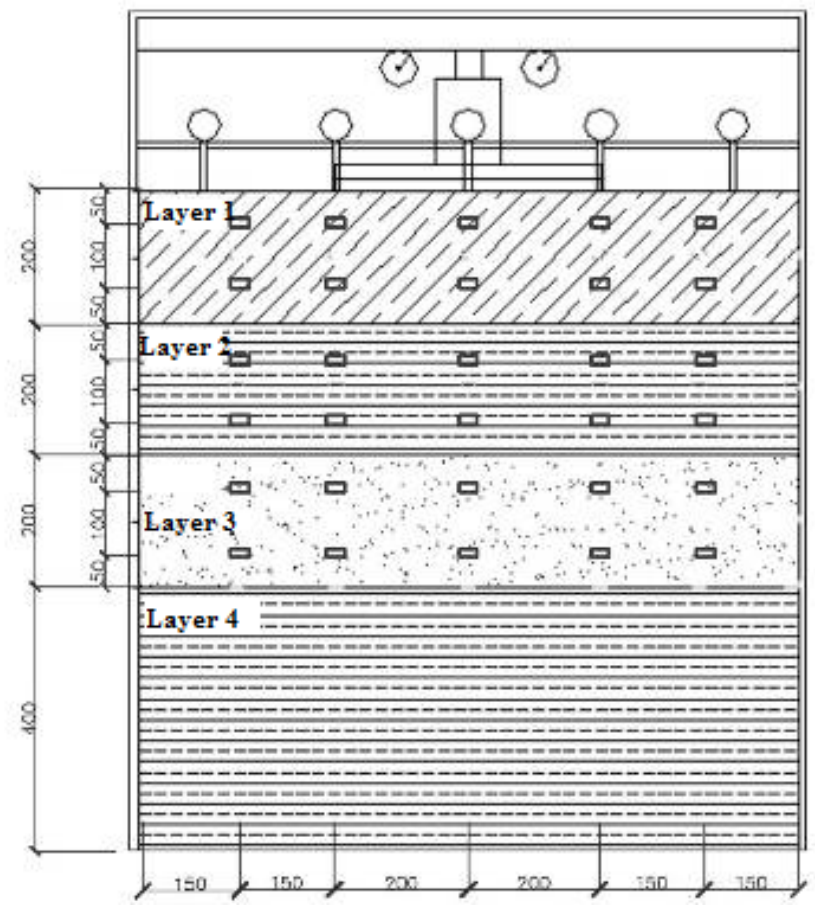

Fig. 2. Scheme of test and set-up of instruments.

Three-layer foundation in experiments consisted of the following subsoils: 
- soft sandy loam, non-subsiding, with the following properties: $\gamma=1.7 \mathrm{~g} / \mathrm{cm}^{3}, W=13 \%$, $\mathrm{E}=5,45 \mathrm{MPa}, \varphi=12-14^{0}, \mathrm{c}=1 \mathrm{kPa}$;

- clay loam, low-plasticity, non-subsiding, with the following properties: $\gamma=1.89 \mathrm{~g} / \mathrm{cm}^{3}$, $W=27 \%, \mathrm{E}=12.4 \mathrm{MPa}, \varphi=19-21^{0}, \mathrm{c}=10 \mathrm{kPa}$;

- fine sand, medium-weight, not enough saturated with the following properties: $\gamma=1.65$ $\mathrm{g} / \mathrm{cm}^{3}, W=13 \%, \mathrm{E}=11 \mathrm{MPa}, \varphi=14-16^{0}, \mathrm{c}=2 \mathrm{kPa}$.

In all experiments semi-solid non-subsiding clay loam with the following properties was used as lower underlayer: $\gamma=2.05 \mathrm{~g} / \mathrm{cm}^{3}, W=16 \%, \mathrm{E}=38 \mathrm{MPa}, \varphi=28^{0}, \mathrm{c}=25 \mathrm{kPa}$.

The following four experiments, which simulate work of slab foundation based on three-layer ground base at rigid underlying layer, were conducted:

1 -st experiment - layers order is described above;

2-d experiment: fine sand, medium-weight;

soft sandy loam, non-subsiding;

clay loam, low-plasticity, non-subsiding

3-d experiment: clay loam, low-plasticity, non-subsiding;

fine sand, medium-weight;

soft sandy loam, non-subsiding.

4-th experiment: fine sand, medium-weight;

clay loam, low-plasticity, non-subsiding;

soft sandy loam, non-subsiding.

We poured the subsoil in layers of $5 \mathrm{~cm}$ into volume flume. After that it was spread and compacted by rectangular-sectioned rammer to predetermined value of density. Soil samples for physical and mechanical characteristics definition were drawn in every layer after soil compaction.

At prepared surface we set the model of slab foundation that represents reinforcedconcrete slab with dimensions of $400 \times 400 \times 40 \mathrm{~mm}$. The load was applied to the slab using a hydraulic cell under the block steps of 250, 500, 750, 1000, $1500 \mathrm{~kg}$.

\section{Results}

During the experiments strains of ground bases were measured by ground sensors which were placed in the plan in two rows in every layer under the center of the slab (Fig. 2). Ground sensors readings were taken by means of AID-4 strain-gauge station. As a result we received relative rates of stress in soil in-situ and rates of settlement of ground in every layer.

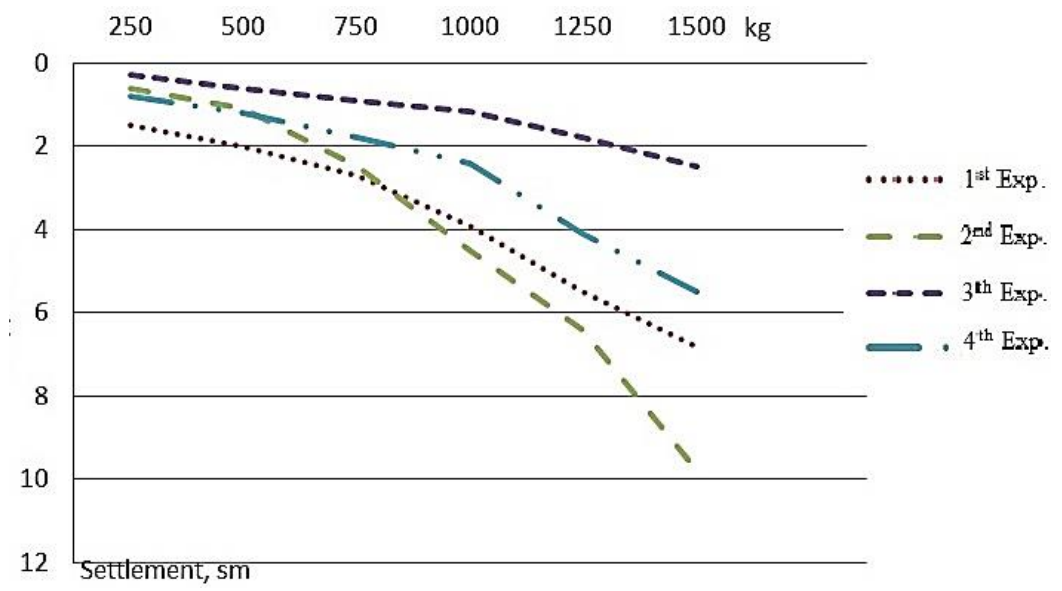

Fig. 3. Dependence of slab settlement on load. 

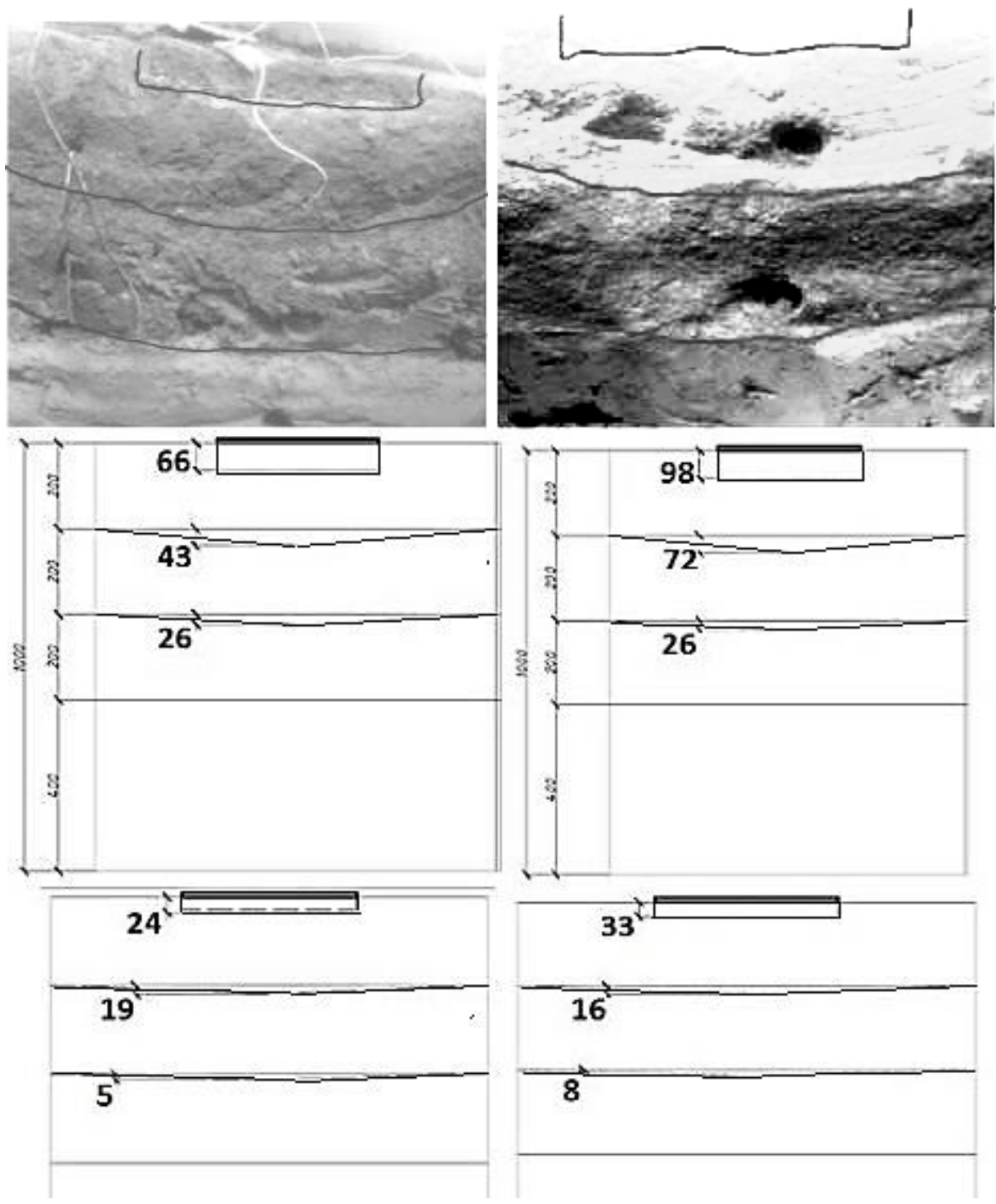

Fig. 4. Section of three-layer ground base in the center of slab model and form of strain of layered ground base in 4 experiments.

Comparing slab settlement received in 4 experiments (Figs. 3, 4) we can see that minimal settlement was received in the $3^{\mathrm{d}}$ experiment and amounts $24 \mathrm{~mm}$, maximum - in the $2^{\text {nd }}$ experiment $-98 \mathrm{~mm}$, in the $3^{\mathrm{d}}$ and $4^{\text {th }}$ experiments rates of settlements differ slightly and are 24 and $33 \mathrm{~mm}$, respectively. The largest value of settlements of slab foundation model appeared in the presence of fine sand or fine sandy loam as underlaying layer. The place of more solid layer - low-plasticity clay loam - has major importance: the closer to surface it is placed, the less is the settlement. It means that solid upper layer in layered foundation largely increases distributing capacity of full compressible layer.

During all experiments (Figs. 5, 6) in the upper two layers at all steps of loading the epure of stress distribution in the subsoils in horizontal direction has classic view of distribution, videlicet saddle-like form; in the $3^{\mathrm{d}}$ layer that is deeper, the epure of stress has 
cusp form; and only during the experiment №3, where layers are arranged from up to down from most firm to less firm, the epure changes its form from saddle-like to cusp one.
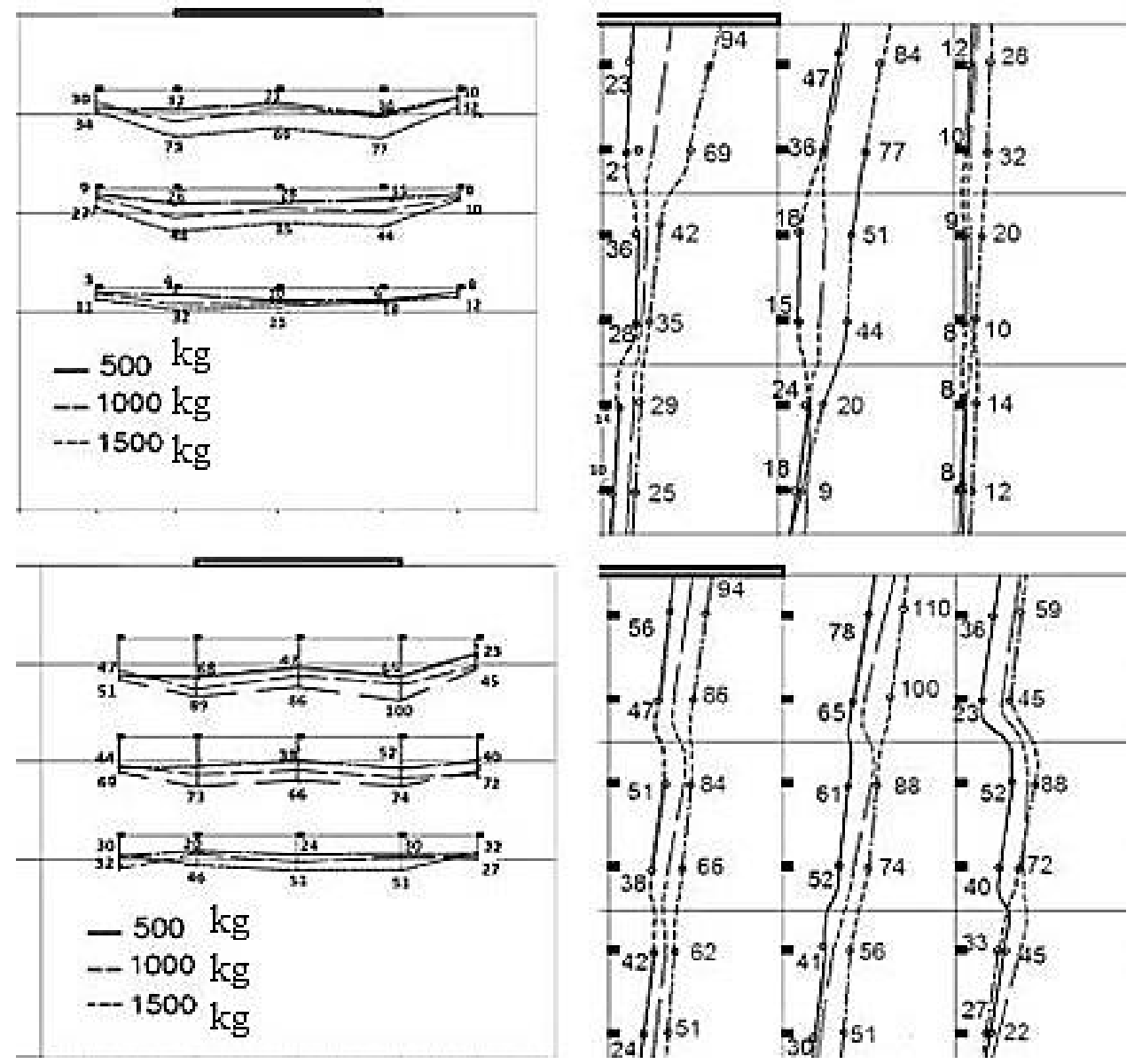

Fig. 5. Stress epures in horizontal and vertical directions in the subsoils under the slab foundation model in $1^{\text {st }}$ and $2^{\text {nd }}$ experiments.

The highest rates of strain up to $140 \mathrm{kPa}$ appear at underlaying layer of slab foundation if it is the most non-rigid ground - clay loam (experiment No 3). In this case of three-layer ground base a high rate of strain can be observed also at other layers: up to $113 \mathrm{kPa}$ in the $2^{\text {nd }}$ layer and up to $110 \mathrm{kPa}$ in the $3^{\mathrm{d}}$ layer. During the experiment №4 where settlement was also small, maximum stresses in layers were observed from up to down: $122 \mathrm{kPa}, 137 \mathrm{kPa}$, $90 \mathrm{kPa}$. During the experiments \#1 and \#2, where settlement was 2-3 times more, maximum stresses in layers were smaller (from up to down) by 55\% (84 kPa) and $18 \%(110 \mathrm{kPa})$, by $145 \%(51 \mathrm{kPa})$ and $42 \%(88 \mathrm{kPa})$, by $212 \%(32 \mathrm{kPa})$ and $79 \%(56 \mathrm{kPa})$. 

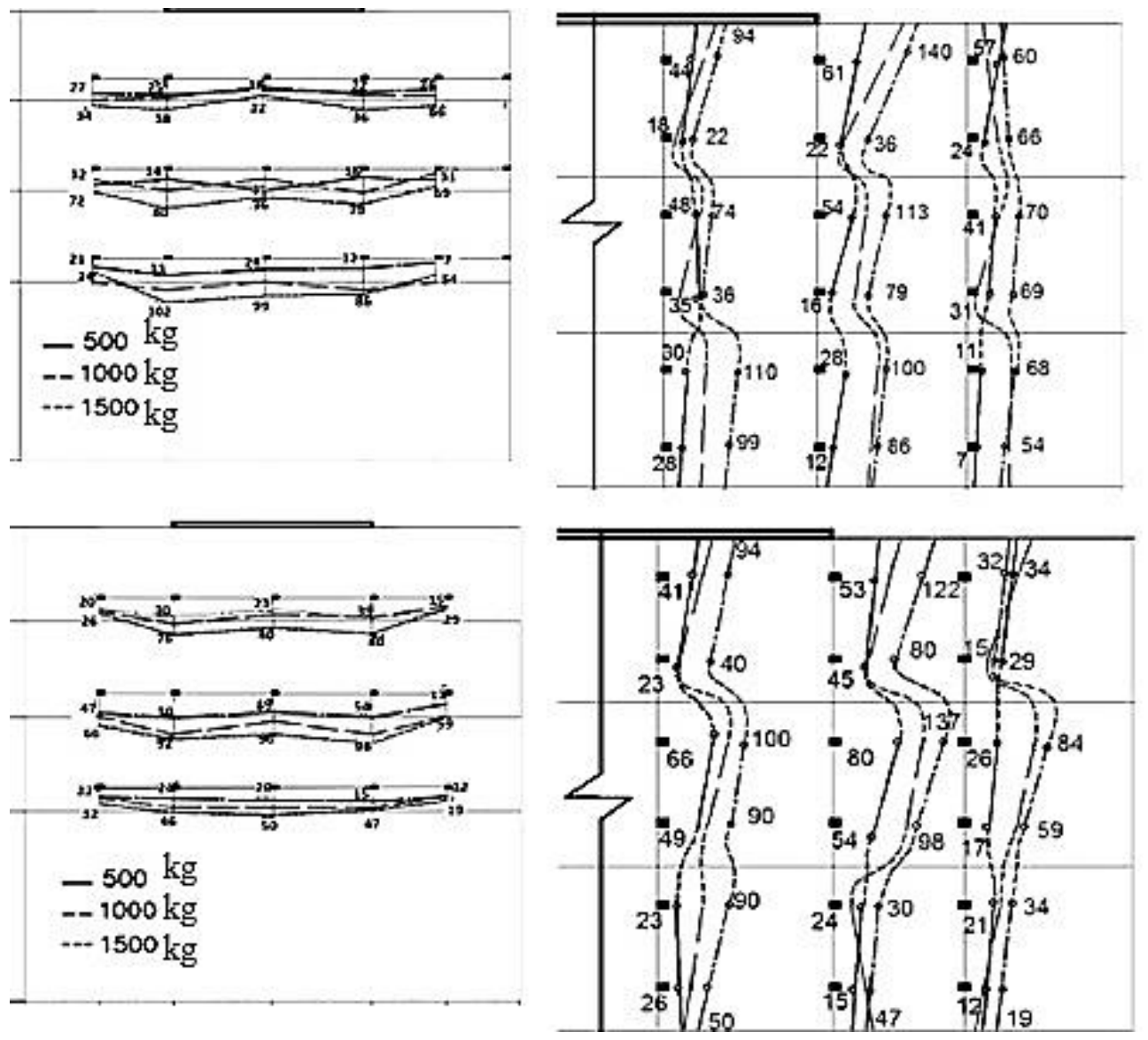

Fig.6. Stress epures in horizontal and vertical directions in the grounds under the slab foundation model in $3^{\text {th }}$ and $4^{\text {th }}$ experiments.

\section{Discussion}

After stress epures of all 4 experiments were analyzed (Figs. 5, 6) we can conclude that stress distribution in layered foundation differs from accepted scheme peculiar to homogeneous foundation.

By the nature of compressive stress distribution (Figs. 5, 6) we can observe that in every geologic layer stress decreases in depth and in the underlying layer in the majority of experiments stress increase can be seen in comparison with upper layer, in other words on the border between layers the leap as stress fluctuation appears that is indicative of shearing stress in contact layer. At the same time, the more these strains, the higher the contact layer is and the more efficiently the compressive stress is redistributed in the layered foundation which leads to less settlements of slab foundation model. During the experiment №1 (settlement is $66 \mathrm{~mm}$ ) compressive stress changes in all three layers almost according to linear law. During the experiment №2 (settlement is $93 \mathrm{~mm}$ ) stress under the center and on the edge of slab changes according to linear law in all depth of foundation and outside of slab there is a stress fluctuation by two times more in the $1^{\text {st }}$ and $2^{\text {nd }}$ layers. During the experiment \#3 (settlement is $24 \mathrm{~mm}$ ) stress fluctuation appears in two contact layers in the center and on the edge of slab by $3.05 \div 3.36$ times more and by $1.27 \div 3.14$ times more respectively, outside of the slab there is no stress fluctuation. During the experiment №4 
(settlement is $33 \mathrm{~mm}$ ) stress fluctuation can be observed only between the $1^{\text {st }}$ and $2^{\text {nd }}$ layers by $1.71 \div 2.9$ times more all along the contact line.

\section{Conclusions}

1. In multilayer ground bases of slab foundations with a significant difference in strength and stress-related characteristics, compressive stress changes in depth according to the scheme that differs from accepted scheme inherent in homogeneous foundation. Stress not only decreases with depth but also can increase at the contacts of lithologically different layers.

2. Stress fluctuation in vertical epures, which can be seen in the place of one layer to other crossing, shows shearing stress in contact layer.

3. Depending on the stratal configuration of different subsoils stress-strain state of layered ground base is variable in wide range.

\section{References}

1. I. T. Mirsayapov, N. N. Aysin, Influence of a deep construction pit on a technical condition of surrounding buildings, dig. of art. International Conference on Geotechnics Fundamentals and Applications in Construction: New Materials, Structures, Technologies and Calculations, GFAC 2019, Saint Petersburg, 197 (2019) DOI: $10.1201 / 9780429058882-38$

2. D. R. Safin, Experimental studies of a weak clay base reinforced with sand piles, IOP Conf. Series: Materials Science and Engineering, 962 (2020) DOI: 10.1088/1757899X/962/3/032020

3. M. A. Shams, M. A. Shahin, M. A. Ismail, Numerical analysis of slab foundations on reactive soils incorporating sand cushions, Computers and Geotechnics, 112, 218 (2019) DOI: 10.1016/j.compgeo.2019.04.026

4. F. E. Sánchez, M. B. Aguado, E. S. Pérez, Probabilistic method to assess model uncertainty of rigid inclusion on a granular fill supporting a slab foundation, Applied Sciences, 10(21) (2020) DOI: 10.3390/app10217885

5. M. A. Shams, M. A. Shahin, M. A. Ismail, Simulating the behaviour of reactive soils and slab foundations using hydro-mechanical finite element modelling incorporating soil suction and moisture changes, Computers and Geotechnics, 98 (2018) DOI: 10.1016/j.compgeo.2018.01.013

6. R. Scarfone, M. Morigi, R. Conti, Assessment of dynamic soil-structure interaction effects for tall buildings: A 3D numerical approach, Soil Dynamics and Earthquake Engineering, 128 (2020) DOI: 10.1016/j.soildyn.2019.105864

7. M. A. Shams, M. A. Shahin, M. A. Ismail, Design of Stiffened Slab Foundations on Reactive Soils Using 3D Numerical Modeling, International Journal of Geomechanics, 20(7) (2020) DOI: 10.1061/(asce)gm.1943-5622.0001654

8. M. Jlilati, V. Brown, X. Tang, Comparative investigation of two design methods for slab-on-grade foundations subjected to concentrated loads, ISEC 2019 - 10th International Structural Engineering and Construction Conference (2019) DOI: 10.14455/isec.res.2019.45

9. D. Kuchárová, G. Lajčáková, Concrete slab on elastic foundation under one axle load, MATEC Web of Conferences, 313 (2020) DOI: 10.1051/matecconf/202031300010 
10. P. Murakonda, P. Maheshwari, Soil-structure interaction of plates on earth beds with geosynthetic inclusion, Indian Geotechnical Journal, 49(3) (2019) DOI: 10.1007/s40098-018-0327-1

11. M. Mohyla, K. Vojtasik, M. Stolarik, Experimentally measurement and analysis of stress under foundation slab, International Journal of GEOMATE, 13(35), 128 (2017) DOI: $10.21660 / 2017.35 .6694$

12. E. Hrubesova, M. Mohyla, H. Lahuta, T. Q. Bui, P. D. Nguyen, Experimental analysis of stresses in subsoil below a rectangular fiber concrete slab, Sustainability (Switzerland), 10(7) (2018) DOI: 10.3390/su10072216

13. T. Bobyleva, A. Shamaev, An Efficient Algorithm for Calculating Rheological Parameters of Layered Soil Media Composed from Elastic-Creeping Materials, Soil Mechanics and Foundation Engineering, 54(4) (2017) DOI: 10.1007/s11204-017-9462-4

14. Z. Xiu, C. Li, F. Wang, J. Qi, Investigation on the deformation behavior of multilayered soils under a large foundation, Dongbei Daxue Xuebao/Journal of Northeastern University, 40(12) (2019) DOI: 10.12068/j.issn.1005-3026.2019.12.020

15. D. Loukidis, G. Tamiolakis, Spatial distribution of Winkler spring stiffness for rectangular mat foundation analysis, Engineering Structures, 153 (2017) DOI: 10.1016/j.engstruct.2017.10.001

16. A. Beskopylny, E. Kadomtseva, G. Strelnikov, Numerical study of the stress-strain state of reinforced plate on an elastic foundation by the Bubnov-Galerkin method, IOP Conference Series: Earth and Environmental Science (2017) DOI: 10.1088/17551315/90/1/012017

17. B. Klemczak, A. Zmij, M. Azenha, Numerical study on restraints effects in massive foundation slabs, Procedia Engineering, 193, 226 (2017) DOI: 10.1016/j.proeng.2017.06.208

18. M. Mirsaidov, Q. Mamasoliev, Contact problems of multilayer slabs interaction on an elastic foundation, IOP Conference Series: Earth and Environmental Science, 614 (2020) DOI: 10.1088/1755-1315/614/1/012089

19. R. Baimakhan, Z. Kadirova, A. Seinassinova, Calculation model of the "buildingfoundation" system on anisotropic base and deformation calculations, Periodicals of Engineering and Natural Sciences, 9(1) (2021) DOI: 10.21533/pen.v9i1.1807

20. C. Li, Z. Xiu, F. Wang, Calculation on deformation of layered sandy with weak interlayer under large foundation, Dongbei Daxue Xuebao/Journal of Northeastern University, 39(4) (2018) DOI: 10.12068/j.issn.1005-3026.2018.04.025

21. D. R. Safin, R. T. Zainullin, Research of bearing capacity and deformability of ground ballast berms, Izvestiya KGASU, 4(46) (2018) 